\author{
Roberto Militerni \\ Carmela Bravaccio \\ Carmelinda Falco \\ Stefano Puglisi-Allegra \\ Tiziana Pascucci \\ Cinzia Fico
}

\section{Pain reactivity in children with autistic disorder}

Received: 19 January 2000

Accepted in revised form: 15 February 2000

\begin{abstract}
Abnormal pain reactivity is often reported by the parents of children with autistic disorder (AD). This is an interesting feature because it could be related to some neurochemical findings frequently reported in autism. The aim of the present study is to report the preliminary findings about pain reactivity in children with autism, and to relate them to serotoninemia. We studied 77 subjects with "primary" AD. Reports of each child's pain reactivity were obtained through a structured interview with the child's parent. In 44 of the 77 children, serotonin blood levels were measured. We found an abnormal pain reactivity in children with autistic disorder when compared with non-autistic children, matched for age, sex, and socio-economic
\end{abstract}

level. The pain reactivity showed a significant correlation with the serotoninemia levels. The data obtained by the present study are interesting, although they must be considered with careful attention, both for the sample size and for methodological difficulties. In fact, in studying this disorder, only the parents' insight can be of help.

Key words Autism • Pain reactivity • Serotonin

\section{Introduction}

Autistic disorder (AD) is defined as a behavioral syndrome that involves severe qualitative deficits in all three of the following domains: (a) social interaction, (b) language communication and play, and (c) activities and interests that are stereotyped, restrictive, and repetitive (DSM-IV) [1]. The clinical picture is also affected by additional features and behaviors. Some children with autism have surprisingly good musical, mathematical, or visuospatial abilities, despite profound deficits in other domains. They may react paradoxically to particular sensory stimuli. Sometimes they are oblivious to pain. Such abnormal pain reactivity is often reported by the parents, but it is difficult to measure. Nevertheless, this is an interesting feature because it could be related to neurochemical find- ings frequently reported in autism. Neurobiological studies suggest abnormalities in the endogenous opioid system [2], and more extensively in the serotoninergic system [3, 4].

The aim of the present study is to report preliminary findings about pain reactivity in children with autism, and to relate them to serotoninemia.

\section{Materials and methods}

Subjects

The sample population was selected from children who were observed in the Child Neuropsychiatry Clinic, Second University of Naples, Italy, over the past 5 years. The inclusion criteria were 
the following: (a) diagnosis of AD made on the basis of the DSMIV criteria; (b) absence of nosographically defined syndromes, such as phenylketonuria, Down syndrome, muscular dystrophy, or fragile X syndrome; (c) absence of complex epileptic syndrome refractory to medication; and (d) age under 11 years. According to such criteria, we selected 77 children, 65 boys and 12 girls, aged between 2.5 and 10.7 years (mean, 5.3 years).

The study also included a control group composed of 32 nonautistic children, matched for age, gender and socio-economic level.

\section{Clinical evaluation}

Cognitive development, autistic symptomatology, and adaptive behavior were evaluated, respectively, with Griffiths' scales [5] and Wechsler intelligence scale for children (WISC-R) [6], childhood autism rating scale (CARS) [7], and Vineland adaptive behavior scales (ABS) [8]. Each child was monitored with a videotaped play session, standardized for time, materials, and type of interaction.

Reports of each child's behavior were obtained through a structured interview with the child's parent. The interview concerned the following areas: psychomotor development, age and pattern of onset of the autistic symptomatology, environmental factors, and the child's actual behaviors, especially as related to pain reactivity.

All children were evaluated clinically with electroencephalography (EEG), brain imaging, auditory brainstem response (ABR), screening test for inborn errors of metabolism, and karyotype determination. Other instrumental or laboratory examinations were performed on the basis of the clinical findings.

In 44 of the 77 children, serotonin blood levels were measured. Blood samples were centrifuged for $25 \mathrm{~min}$ at $4^{\circ} \mathrm{C}$ at $140 \mathrm{x}$ g within 20 min after venipuncture, according to standard protocols [9]. One milliliter supernatant phase, the platelet-rich plasma (PRP), was stored at $-80^{\circ} \mathrm{C}$ and assessed by high-performance liquid chromatography (HPLC), as previously described [10, 11]. These 44 subjects were included in a multicentric study on genetic aspects of autism, coordinated by the Laboratory of Neuroscience, Libera Università Campus Bio-Medico, Rome, Italy.

\section{Pain reactivity evaluation}

Information on each child's behavior related to pain reactivity was obtained during the structured interview. If the parent reported an abnormal reaction to nociceptive stimuli, the interviewer asked a series of follow-up questions. The follow-up questions were designed to obtain more detailed information about the frequency of the abnormal reactions (sometimes or always), the kind of stimuli in which the child showed "analgesia" (i.e. accidental trauma, medical interventions, trauma caused by other children), and the situation in which the abnormal reaction occurred (at home, at school, etc.).

The behaviors described in the parents' answers were coded into categories after the completion of the data collection. The categories were the following:
1. Normal pain reactivity (NPR). No abnormal reactions were described;

2. Low pain reactivity (LPR). Abnormal reaction to pain was discontinuous or related to a particular stimulus or situation;

3. Very low pain reactivity (VLPR). Abnormal reactions were constant regardless of the kind of stimulus and situations.

The interview was also carried out with the parents of the 32 non-autistic children in the control group.

\section{Statistical analysis}

The probability level ( $p$ value) was evaluated by Student's $t$ statistics, $\chi^{2}$ test, and regression analysis.

\section{Results}

In autistic children, the pain reactivity was low (LPR) in $22 \%$ and very low (VLPR) in $21 \%$. The percentages of LPR and VLPR in the control group were, respectively, $7 \%$ and $3 \%\left(\chi^{2}=11.550 ; p<.005\right)$ (Table 1$)$.

For autistic children, we examined the relationship between pain reactivity and the following variables: age, development quotient (DQ), CARS score, Vineland ABS score, and serotoninemia (Table 2). No significant correlation was observed, except for serotoninemia $(r=.329 ; p<.05)$. The difference in blood serotonin levels between the NPR and VLPR groups was statistically significant $(\mathrm{t}=2.220 ; \mathrm{df}=32$; $p<.05)$.

\section{Discussion}

The results of the present study suggest an abnormal pain reactivity in children with autistic disorder when compared with nonautistic children. However, great caution is necessary in interpreting this finding [12]. We can only refer to parents' impressions. The age of the children and the nature of the disorder make it difficult to measure the pain thresh-

Table 1 Frequency distribution of pain reactivities determined from the structured interview with parents, by study group

\begin{tabular}{|c|c|c|}
\hline \multirow[b]{2}{*}{ Pain reactivity } & \multicolumn{2}{|c|}{ Children, n (\%) } \\
\hline & $\mathrm{AD}(\mathrm{n}=77)$ & Control $(n=32)$ \\
\hline Normal & 44 (57) & $29(91)$ \\
\hline Low & 17 (22) & $2 \quad(6)$ \\
\hline Very low & $16(21)$ & $1 \quad(3)$ \\
\hline
\end{tabular}


Table 2 Clinical features of the 77 autistic children according to pain reactivity classification

\begin{tabular}{|c|c|c|c|c|c|c|c|c|c|c|}
\hline \multirow[b]{3}{*}{ Clinical variable } & \multicolumn{8}{|c|}{ Pain reactivity } & \multirow[b]{3}{*}{$r^{\mathrm{a}}$} & \multirow[b]{3}{*}{$p$} \\
\hline & \multicolumn{2}{|r|}{ Normal } & \multicolumn{3}{|c|}{ Low } & \multicolumn{3}{|c|}{ Very low } & & \\
\hline & $\mathrm{n}$ & Mean (SD) & $\mathrm{n}$ & Mean & (SD) & $\mathrm{n}$ & Mean & (SD) & & \\
\hline Age (years) & 44 & $(2.1)$ & 17 & 5.0 & (1.4) & 16 & 4.5 & (2.3) & .072 & ns \\
\hline $\mathrm{DQ}$ & 44 & $51.6(21.7)$ & 17 & 53.6 & $(27.4)$ & 16 & 56.0 & $(22.1)$ & .079 & $\mathrm{~ns}$ \\
\hline CARS score & 44 & $39 \quad(4.3)$ & 17 & & (3.6) & 16 & 40 & $(2.9)$ & .133 & ns \\
\hline Vineland $\mathrm{ABS}^{2}$ & 44 & $42.3(16.0)$ & 17 & 43.9 & $(17.4)$ & 16 & 34.6 & (13.4) & .184 & ns \\
\hline Blood serotonin (ng/ml) & 25 & $197 \quad(103)$ & 10 & 232 & (106) & 9 & 292 & $(128)$ & .329 & $<.05$ \\
\hline
\end{tabular}

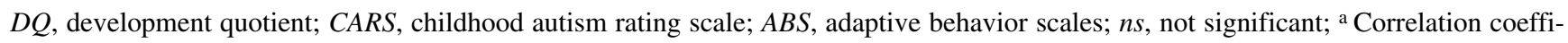
cients determined using pain reactivity as dependent variable; ${ }^{\mathrm{b}}$ Composite standard scores

old. A communication disorder does not allow for checklist and self-reporting measures [13]. The abnormal reaction to body contact precludes using standardized situations, such as intramuscular injections or venipuncture for medical purposes [14], because an autistic child can have violent panic attacks just when touched. Furthermore, the faces pain scale $[13,15]$ is useless because a child with autistic disorder typically shows poor modulation of the emotions with inappropriate body expressions.

In spite of these methodological limitations, abnormal pain reactivity is an interesting feature because it may represent the clinical expression of neurochemical dysfunc- tions reported in autism. For example, a significant correlation between pain reactivity and serotoninemia was found. This finding has never been reported in studies regarding autism. Interestingly, the association between serotoninemia and pain threshold was also found in subjects with temporomandibular joint pain [16-18]. These findings fall within research on the key role of the serotoninergic system in the descending cortical control of nociceptive processing [19].

The data obtained in our study are interesting, but must be considered with careful attention both for the sample size and for the methodological difficulties. In fact, in studying autistic children, only the parents' insight can be of help.

\section{References}

1. - (1994) Diagnostic and statistical manual of mental disorders, 4th edn. American Psychiatric Association, Washington DC

2. Gillberg C (1995) Endogenous opioids and opiate antagonists in autism: brief review of empirical findings and implications for clinicians. Dev Med Child Neurol 37:239-245

3. Cook EH, Leventhal BL (1996) The serotonin system in autism. Curr Opin Pediatr 8:348-354

4. Singh VK, Singh EA, Warren RP (1997) Hyperserotoninemia and serotonin receptor antibodies in children with autism but not mental retardation. Biol Psychiatry 41:753-755

5. Griffiths R (1992) Griffiths mental developmental scales. The Test Agency Limited North Dean, High Wicombe Bucks (UK)

6. Wechsler D (1974) Wechsler intelligence scale for children, Revised. Psychological Corporation, New York
7. Schopler E, Reichler RJ, Renner BR (1988) The childhood autism rating scale (CARS). Western Psychological Services, Los Angeles

8. Sparrow RS, Balla DA, Cicchetti DV (1984) Vineland adaptive behavior scales. Survey form. American Guidance Service, Circle Pines

9. Rolf LH, Haarmann FY, Grotemeyer K-H, Keher H (1993) Serotonin and aminoacid content in platelets of autistic children. Acta Psychiatr Scand 87:312-316

10. Kempf E, Mandel P (1981) Reversephase high-performance liquid chromatographic separation and electrochemical detection of norepinephrine, dopamine, serotonin and related major metabolites. Anal Biochem 112:223-231

11. Cabib S, Puglisi-Allegra S (1994) Opposite responses of mesolimbic dopamine system to controllable and uncontrollable aversive experiences. J Neurosci 14:3333-3340
12. Boureau F, Luu M, Boubrere JF (1990) Problems posed by the evaluation of pain and its psychological aspects. Neurophysiol Clin 20:357-368

13. Goodenough B, Addicoat L, Champion GD, McInerney M, Young B, Juniper K, Ziegler JB (1997) Pain in 4- and 6year-old children receiving intramuscular injections: a comparison of the faces pain scale with other self-report and behavioral measures. Clin J Pain 13:60-73

14. Tordjman S, Antoine C, Cohen DJ, Gauvain-Piquard A, Carlier M, Roubertoux P, Ferrari P (1999) Etude des conduites auto-agressives, de la réactivité à la douler et de leurs interrelations chez les enfants autistes. Encéphale 25:122-134 
15. Bieri D, Reeve RA, Champion GD, Addicoat L, Ziegler JB (1990) The faces pain scale for the self-assessment of the severity of pain experienced by children: development, initial validation, and preliminary investigation for ratio scale properties. Pain 41:139-150

16. Ernberg M, Hedenberg-Magnusson B, Alstergren P, Kopp S (1999) The level of serotonin in the superficial masseter muscle in relation to local pain and allodynia. Life Sci 65:313-325
17. Alstergren P, Ernberg M, Kopp S, Lundeberg T, Theodorsson E (1999) TMJ pain in relation to neuropeptide $\mathrm{Y}$, serotonin, and interleukin 1-beta in rheumatoid arthritis. J Orofac Pain 13:49-55

18. Ernberg M, Hedenberg-Magnusson B, Alstergren P, Lundeberg T, Kopp S (1999) Pain, allodynia, and serum serotonin level in orofacial pain of muscular origin. J Orofac Pain 13:56-62
19. Kharkevich DA, Churukanov W (1999) Pharmacological regulation of descending cortical control of the nociceptive processing. Eur J Pharmacol 375:121-131 